\title{
LASER DIODE NEAR-INFRARED TRANSILLUMINATION (DIAGNOCAM) AS A DIAGNOSTIC TOOL IN EARLY DETECTION OF CARIES (IN VITRO STUDY)
}

\author{
Amir N. El-Kholi ${ }^{1} B D S$, Samir A. Koheil ${ }^{2} P h D$, Mona M. Ghoneim ${ }^{3} P h D$
}

\begin{abstract}
INTRODUCTION: The importance of early detection before the development of irreversible damage is now generally accepted. Most studies do not report the presence of non cavitated lesions, though they have been shown to have predictive value.

OBJECTIVES: Validate LASER diode near-infrared transillumination (DIAGNOcam) as a diagnostic instrument in the early detection of noncavitated carious lesions.

MATERIALS AND METHODS: Thirty three extracted sound premolars were examined on both approximal surfaces by (D1) EDX to determine $\mathrm{Ca} / \mathrm{P}$ ions ratio (1.8 $\leq$ ), (D2) Periapical Digital Radiography, and (D3) LASER diode near-infrared transilluminated using DIAGNOcam. Any defect that indicated cavities by any of the mentioned methods discarded the tooth. To confirm that the selected sound teeth were intact, three teeth were randomly selected and invasively imaged by Scanning Electron Microscopy. The remaining thirty teeth were covered with acid resistant varnish except in 3x3mm in approximal areas and were immersed in a demineralizing solution for $72 \mathrm{H}$ Then, the teeth were then re-examined using D1, D2 \& D3. To confirm that the results obtained, three teeth were randomly selected and invasively imaged by Scanning Electron Microscopy.

RESULTS: D1 detected (100\%) Ca/P ions ratio less than 1.8 (demineralized), D2 detected (6.67\%) with enamel radiolucency and (93.33\%) without any radiolucency, while D3 detected (100\%) demineralized enamel. Pearson's Chi square test as well as validity tests showed that there is a statistically significant difference between D2 and the other diagnostic means (D1 and D3). SEM showed evidence of enamel demineralization in the three randomly selected teeth.

CONCLUSIONS: LASER diode near-infrared transillumination (DIAGNOcam) is a reliable and valid method in detecting early enamel caries demineralization.
\end{abstract}

KEYWORDS: DIAGNOcam, LASER diode near-infrared transillumination, early detection, noncavitated lesions.

1. Demonstrator at the Conservative Department, Alexandria University.

2. Professor of Operative Dentistry, Conservative Department, Alexandria University.

3. Assistant Professor of Operative Dentistry, Conservative Department, Alexandria University.

Corresponding author:

E-mail: amir.kholi@gmail.com

\section{INTRODUCTION}

Dental caries is the most prevalent dental diseases in the world. It is a multi-factorial disease formed by a complex interaction between acid-producing bacteria and fermentable carbohydrate (1). The accumulation of microbial plaque to the enamel surface, initiates the carious surface dissolution which in turn proceeds to subsurface demineralization (2). As intervention and treatment should become with a micro-minimally invasive approach (3). Ideally, caries detection methods should capture the whole caries process, from the beginning of early demineralization through the cavitation stage. It should be accurate and easy to apply for all surfaces of teeth, also for lesions adjacent to restorations (4).

Detection of carious lesions on neighboring approximal surfaces of posterior teeth is also a challenge (5). The sensitivity of dental radiographs (Periapical, Panoramic \& Posterior Bitewing) in detecting evidence of dental caries is lower than expected, rarely showing more than $60 \%$ of the lesions (6). Which means, by using only conventional clinical and radiographic methods, the dentist will detect only cavities (3). In general, cavitated lesions are the ones being recorded; however, there is an understanding among researchers that the detection of the caries process has progressed far beyond the point of confining the evidence for dental caries at the cavitation level involving enamel or both enamel and dentin. Hence, recording carious lesions only at the cavitation level is no longer acceptable by researchers (4).

Non-invasive treatment of early caries lesions by remineralization has become of major importance in clinical daily practice, where many studies in turn would prevent white spot lesions formation and further cavitation (7). Sound enamel is comprised of modified hydroxyapatite crystals that are closely packed, producing a semi transparent structure. The color of teeth is strongly affected by the dentin shade lying beneath. When enamel is disrupted, for instance in the presence of demineralization, the penetrating photons of light are scattered (they tend to change direction, although do not loose energy) which results in an optical disruption (8). A new LASER diode near infrared transillumination digital video camera known as (DIAGNOcam) records the image and displays it live on a computer screen, using KaVo KiD V 2.4 software demineralized lesions are displayed as dark shadows. The images recorded can be stored, allowing the determination of early demineralization without using a radiograph, thus significantly simplifying monitoring and patient communication. 
The purpose of this study is to determine the validity of that device for the diagnosis of early enamel demineralization before cavitation, enabling the practitioner to treat instead of fill the tooth.

\section{MATERIALS AND METHODS}

Thirty-three sound human premolars were extracted for orthodontic indications at the department of Oral and Maxillofacial Surgery (Faculty of Dentistry - Alexandria University) with a written consent signed by the patients. The teeth were free from any visually detected carious lesions. The chosen teeth were stored in a thymol saturated saline to prevent any bacterial growth, rinsed in $10 \%$ sodium hypochlorite solution for $20 \mathrm{~min}$, followed by rinsing in distilled water for $20 \mathrm{~min}$. All the thirty three were visually inspected to detect any discoloration, cracks, white spots or anything that looked to interfere with normal enamel and were subjected to the following diagnostic tools and named (D1, D2 \& D3) accordingly. The following sequence of examination was performed to make sure that all the specimen's enamel was free from any demineralized carious lesions. D1: Thirty three extracted visually sound premolars were examined by energy dispersive $\mathrm{x}$-ray spectrometry (EDX), which was performed to detect Calcium and Phosphorus ions concentration just below the contact areas of the mesial and distal surfaces of the teeth in order to calculate the $\mathrm{Ca} / \mathrm{P}$ ions ratio. Any tooth with a ratio less than 1.8 on either of its sides was considered a demineralized carious tooth according to ten Cate, JM (9) and Jalevik, B. (10). The whole system consists of control panel with a monitor as well as the scanning microscopy unit where the EDX device is mounted and a computer which is connected to the whole system to save the results obtained through a computer software (ISIS v2.4). The procedure started by dehydration of teeth by a desiccator. Each tooth was introduced in the scanning electron microscopy and a $3 \times 3 \mathrm{~mm}$ just below the contact area of mesial surface of the tooth to be examined by EDX was determined and using ISIS computer software and a graph was obtained showing both Calcium and Phosphorus ions content on the area examined. The same procedure was performed for a $3 x 3 \mathrm{~mm}$ just below the contact area of the distal surfaces as well. The resulting concentrations were used to calculate the Calcium and Phosphorous ions ratio and any tooth with $\mathrm{Ca} / \mathrm{P}$ ions ratio less than 1.8 on any of its sides was discarded, replaced by another tooth and examined as mentioned previously. D2: The obtained thirty three teeth from D1, were examined using periapical digital radiography showing both mesial and distal surfaces. The teeth were fixed by soft wax at the tip of their roots in a vertical position with the digital sensor placed in a vertical manner lingual to them and the cone positioned from the buccal for paralleling technique with a radiation dose of $0.19 \mathrm{~s} / \mathrm{mGy}$. Any tooth showing radiolucencies on either of its mesial or distal surfaces that indicated caries was replaced by another tooth and re-examined in the previously mentioned sequence of D1. D3: The obtained thirty three sound teeth from D1 and D2 were imaged on both mesial and distal surfaces using LASER diode near infrared transillumination operating at $788 \mathrm{~nm}$ wavelength (DIAGNOcam) which is a fluorescent LASER device for caries detection. DIAGNOcam produces images reminiscent of X-ray images, but which are completely radiation free by means of a LASER beam that is especially adapted to this examination method, it is delivered with a computer-based image processing software for showing / displaying, storing / saving the images, and for optional recording of live streams. The tooth structures allow the passage of the LASER beam from the entry site to the camera. Areas that block LASER beam transmission (e.g. demineralized carious lesions) show up clearly as well delimited, dark areas. A digital camera captures the actual situation and makes it visible in real time on the screen. DIAGNOcam images were obtained from an occlusal view in a dark room setting to simulate the situation inside the oral cavity. Each tooth had two images captured, all from the occlusal view; one taken from the occlusal aspect with $18^{\circ}$ tilting towards the mesial surface and one with $18^{\circ}$ tilting towards the distal surface. The degree of inclination was measured using iLevel LITE High Precision Clinometer v 1.0 mobile app. Any tooth showing defects by a dark area in the images that indicated demineralization or caries was replaced by another tooth and re-examined in the previously mentioned sequences of D1 and D2. Scanning electron microscopy: (Descriptive images) three teeth were randomly selected out of the thirty three that were diagnosed as sound teeth in D1, D2 and D3. They were gold sputtered and invasively imaged on the $3 \times 3 \mathrm{~mm}$ just below the contact area of both their mesial and distal surfaces by scanning electron microscopy at $25 \mathrm{KV}$ and $\mathrm{x} 1000$ magnification to check the absence of micro porosities on the examined areas of the teeth. The remaining thirty teeth were mounted in acrylic cylindrical blocks with their crowns and the coronal third of their roots visible both measuring $16 \mathrm{~mm}$, leaving the rest of the root in the acrylic block to facilitate the use of DIAGNOcam and allow proper imaging of the approximal areas. A window of 3x3 mm was identified just below the contact area of the proximal surface by a ruler and the crown of each tooth and the remaining tooth surfaces were covered with Hoffmann copal varnish Preparation of the demineralizing solution according to Murdoch-Kinch, C. (11): $50 \mathrm{mmol}$ acetic acid, $2.2 \mathrm{mmol} \mathrm{Ca}$ (NO3)2, $2.2 \mathrm{mmol} \mathrm{KH2PO} 4$ and $0.1 \mathrm{ppm} \mathrm{NaF}$. $\mathrm{pH}$ was adjusted to 4.5 by addition of $\mathrm{KOH}$ solution. All the thirty teeth were immersed for 72 hours in demineralizing solution and examined afterwards in the same sequence of diagnostic instruments explained earlier after removal of the varnish using acrylic monomer (14) to allow better penetration of the LASER beam, thus better transillumination. (D1): Calcium and Phosphorous ions ratios of the thirty teeth were re-examined, calculated by EDX and the results were recorded. (D2): Re-imaged by periapical digital radiography for the same thirty teeth and the results were recorded. (D3): Re-imaged by LASER diode near infrared transillumination (DIAGNO cam) for the same thirty teeth and the results were recorded. Three teeth were randomly selected out of the thirty teeth and invasively imaged by scanning electron microscopy on the middle third of both mesial and distal surfaces to confirm demineralization. All (D1) EDX data obtained was statistically evaluated concerning their calcium and phosphorous content. All the images obtained by (D2) Digital radiography and (D3) DIAGNOcam were statistically analyzed using a qualitative criterion (Maia, A. et al) (15) to determine the presence of caries changes on each approximal surface in which: (0) sound enamel, (1) Enamel caries, (2) Caries reaching but not crossing the enamel-dentine junction, (3) Caries into dentine. Statistical 
analysis: The obtained data and images were statistically analyzed by SPSS version 20 software using Pearson's Chi square significance test. Also, validity test was executed, which is the extent to which a test measures what it is supposed to measure; in other words, it is the accuracy of the test. Validity is measured by sensitivity, specificity, positive predictive value and negative predictive value. Sensitivity $=($ true positive $) /($ true positive + false negative $)$ Specificity $=$ (true negative $) /($ true negative + false positive $)$ Positive predictive value $=($ true positive $) /($ true positive + false positive) Negative predictive value $=$ (true negative) $/$ (false negative + true negative)

\section{RESULTS}

The selected teeth prepared for the study were diagnosed as sound by all diagnostic means used. Visually all teeth looked sound without discoloration, cracks, white spots or anything that looked to interfere with normal enamel. D1: The mesial surfaces showed a Calcium ions range between 84.3\% and $64.9 \%$, a Phosphorus ions range of $35.1 \%$ and $15.7 \%$ and a $\mathrm{Ca} / \mathrm{P}$ ions ratio range between 5.3758 and 1.849. The average $\mathrm{Ca} / \mathrm{P}$ ions ratio is 2.4044 . The distal surfaces showed a Calcium ions range between $84.3 \%$ and $64.9 \%$, Phosphorus ions range between $35.6 \%$ and $28.8 \%$ and a $\mathrm{Ca} / \mathrm{P}$ ions ratio range between 2.8949 and 1.809 . The average $\mathrm{Ca} / \mathrm{P}$ ions ratio is 2.1546. D2: All radiographic images obtained showed sound enamel (Score 0 ) on both their mesial and distal sides. D3: All DIAGNOcam images obtained showed sound enamel (Score 0) on the mesial and distal surfaces of the teeth. All scanning electron microscopy images examined randomly showed completely sound prismless intact enamel with no surface demineralization or porosities on both mesial and distal sides of the teeth.

(72 hours demineralization) as shown in figure (1): D1: All the thirty EDX results obtained of the mesial and distal surfaces showed a mesial surface Calcium ions range between $56.5 \%$ and $49.4 \%$, a Phosphorus ions range between $50.6 \%$ and $43.5 \%$ and a $\mathrm{Ca} / \mathrm{P}$ ions ratio range between 1.3006 and 0.9761 . The average $\mathrm{Ca} / \mathrm{P}$ ions ratio is 1.1404. The distal surface Calcium ions range is between $56.3 \%$ and $44.9 \%$, Phosphorus ions range between $55.1 \%$ and $43.7 \%$ and the $\mathrm{Ca} / \mathrm{P}$ ions ratio range between 1.2682 and 0.9481 . The average $\mathrm{Ca} / \mathrm{P}$ ions ratio is 1.0774 . $\mathrm{D} 2$ : Radiographic images showed only four teeth with radiolucencies extended to enamel only (Score 1) on one of their proximal surfaces from which two were on the mesial surfaces while the other two were on the distal surfaces. The remaining twenty six teeth showed sound enamel (Score 0) on both their mesial and distal surfaces. D3: DIAGNOcam images showed all the thirty teeth with carious demineralization (Score 1) on both their mesial and distal surfaces, making a total of sixty surfaces with demineralized carious enamel (Score 1). All scanning electron microscopy images examined randomly showed demineralized carious enamel with irregular pattern of surface destruction on both mesial and distal sides of all the three teeth appearing as hap hazardous thin splits, as well as the typical honeycomb appearance indicating prismatic pattern destruction where the prism cores have been destroyed with remaining interprismatic substance which is less affected.

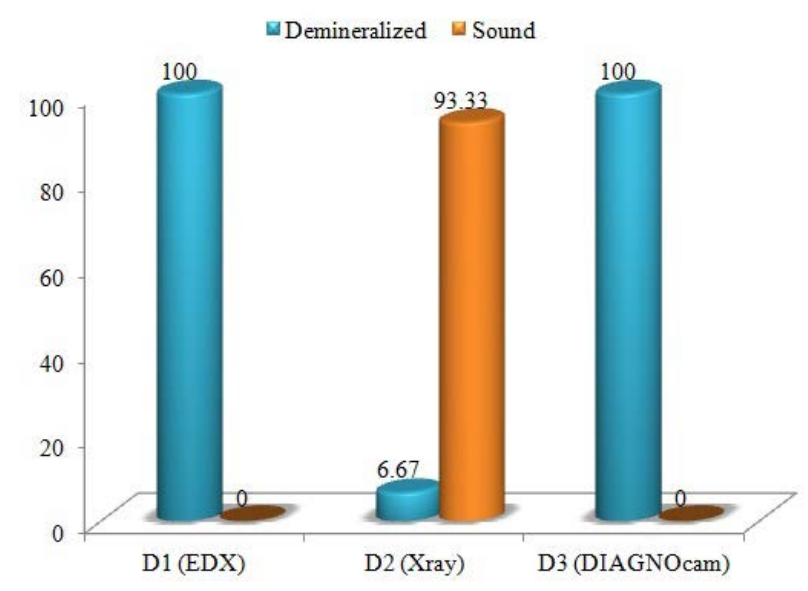

Figure (1): Showing the results obtained after 72 hours of demineralization.

Accuracy of D1 vs. D2 as shown in table (1): At the mesial sides, statistical comparison of the two diagnostic means D1\& D2 showed that D1 is more accurate than D2 in detection of early carious demineralization and the differences are statistically significant. $(\mathrm{X} 2(\mathrm{Y})=22.63, \mathrm{P}$ $\left.(Y)=0.000^{*}\right)$. At the distal sides, statistical comparison of the two diagnostic means D1\& D2 showed that D1 is more accurate than D2 in detection of early carious demineralization and the differences are statistically significant. $\left(\mathrm{X} 2(\mathrm{Y})=22.63, \mathrm{p}(\mathrm{Y})=0.000^{*}\right)$. At both mesial and distal sides, statistical comparison of the two diagnostic means D1\& D2 showed that D1 is more accurate than D2 in detection of early carious demineralization and the differences are statistically significant as shown in table (4). $(\mathrm{X} 2(\mathrm{Y})=48.82, \mathrm{P}(\mathrm{Y})=0.000 *)$.

Table (1): Pearson's Chi square test of significance after 72 hours of demineralization D1 vs. D2.

\begin{tabular}{|c|c|c|c|c|c|c|}
\hline & \multicolumn{4}{|c|}{ Side } & \multirow{2}{*}{\multicolumn{2}{|c|}{ All }} \\
\hline & \multicolumn{2}{|c|}{ Mesial } & \multicolumn{2}{|c|}{ Distal } & & \\
\hline & $\mathbf{N}$ & $\%$ & $\mathbf{n}$ & $\%$ & $\mathbf{n}$ & $\%$ \\
\hline $\begin{array}{l}\text { (D1) EDX } \\
-\quad \text { No caries } \\
-\quad \text { Caries }\end{array}$ & $\begin{array}{c}0 \\
30\end{array}$ & $\begin{array}{c}0.00 \\
100.00\end{array}$ & $\begin{array}{c}0 \\
30\end{array}$ & $\begin{array}{c}0.00 \\
100.00\end{array}$ & $\begin{array}{c}0 \\
60\end{array}$ & $\begin{array}{c}0.00 \\
100.00\end{array}$ \\
\hline $\begin{array}{l}\text { (D2) X-ray } \\
-\quad \text { No caries } \\
-\quad \text { Caries }\end{array}$ & $\begin{array}{c}28 \\
2\end{array}$ & $\begin{array}{c}93.33 \\
6.67\end{array}$ & $\begin{array}{c}28 \\
2\end{array}$ & $\begin{array}{c}93.33 \\
6.67\end{array}$ & $\begin{array}{c}56 \\
4\end{array}$ & $\begin{array}{c}93.33 \\
6.67\end{array}$ \\
\hline Test of significance & \multicolumn{2}{|c|}{$\begin{array}{l}X 2(Y)=22.63 \\
p(Y)=0.000^{*}\end{array}$} & \multicolumn{2}{|c|}{$\begin{array}{l}\mathrm{X} 2(\mathrm{Y})=22.63 \\
\mathrm{p}(\mathrm{Y})=0.000^{*}\end{array}$} & \multicolumn{2}{|c|}{$\begin{array}{l}\mathrm{X} 2(\mathrm{Y})=48.82 \\
\mathrm{p}(\mathrm{Y})=0.000^{*}\end{array}$} \\
\hline
\end{tabular}

X2: Pearson's Chi square

*: Statistically significant $(\mathrm{p}<0.05)$

$\mathrm{Y}$ : Yate's (continuity) corrected Pearson's Chi-squared test 
Table (4): Inter-rater agreement test after 72 hours of demineralization D1 vs. D2.

\begin{tabular}{||l|c|c|c||}
\hline \multirow{2}{*}{} & \multicolumn{2}{|c||}{ EDX } & \multirow{2}{*}{} \\
\cline { 2 - 3 } & -ve & +ve & \\
\hline $\begin{array}{l}\text { X-ray } \\
\text { No caries } \\
\text { Caries }\end{array}$ & 0 & 56 & $56(93.33 \%)$ \\
\hline & 0 & 4 & $4(6.67 \%)$ \\
\hline & 0 & 60 & 60 \\
\hline Sensitivity & Value & $\mathbf{9 5 \%}$ CI & \\
\hline Specificity & $6.67 \%$ & $0.82 \%-22.07 \%$ & \\
\hline Positive likelihood ratio & NA & & \\
\hline Negative Likelihood ratio & 0.07 & & \\
\hline Disease prevalence & $100.00 \%$ & $88.43 \%-100.00 \%$ & \\
\hline Positive predictive value & $100.00 \%$ & & \\
\hline Negative predictive value & $0.00 \%$ & & \\
\hline Overall accuracy & $6.67 \%$ & $0.82 \%-22.07 \%$ & \\
\hline
\end{tabular}

Weighted kappa $=0.000$

The $\mathrm{Z}$ test is -7.2457 . The $\mathrm{p}$-value is $0.000 *$. The result are significant at $\mathrm{p}<0.05$.

Accuracy of D1 vs. D3 as shown in table (2): At the mesial sides, statistical comparison of the two diagnostic means D1 and D3 was not applicable as both methods showed exact match in their results in detection of early carious demineralization. (NA). At the distal sides, statistical comparison of the two diagnostic means D1 and D3 was not applicable as both methods showed exact match in their results in detection of early carious demineralization (NA). At both mesial and distal sides, statistical comparison of the two diagnostic means D1 and D3 was not applicable as both methods showed exact match in their results in detection of early carious demineralization as shown in table (5).

Table (2): Pearson's Chi square test of significance after 72 hours of demineralization D1 vs. D3.

\begin{tabular}{|c|c|c|c|c|c|c|}
\hline & \multicolumn{4}{|c|}{ Side } & \multirow{2}{*}{\multicolumn{2}{|c|}{ All }} \\
\hline & \multicolumn{2}{|c|}{ Mesial } & \multicolumn{2}{|c|}{ Distal } & & \\
\hline & $\mathbf{N}$ & $\%$ & $\mathrm{n}$ & $\%$ & $\mathrm{n}$ & $\%$ \\
\hline $\begin{array}{l}\text { (D1) EDX } \\
\text { - No caries } \\
\text { - Caries }\end{array}$ & $\begin{array}{c}0 \\
30\end{array}$ & $\begin{array}{c}0.00 \\
100.00\end{array}$ & $\begin{array}{c}0 \\
30\end{array}$ & $\begin{array}{c}0.00 \\
100.00\end{array}$ & $\begin{array}{c}0 \\
60\end{array}$ & $\begin{array}{c}0.00 \\
100.00\end{array}$ \\
\hline $\begin{array}{l}\text { (D3)DIAGNOcam } \\
- \text { No caries } \\
- \text { Caries }\end{array}$ & $\begin{array}{c}0 \\
30\end{array}$ & $\begin{array}{c}0.00 \\
100.00\end{array}$ & $\begin{array}{c}0 \\
30\end{array}$ & $\begin{array}{c}0.00 \\
100.00\end{array}$ & $\begin{array}{c}0 \\
60\end{array}$ & $\begin{array}{c}0.00 \\
100.00\end{array}$ \\
\hline Test of significance & \multicolumn{2}{|c|}{ NA } & \multicolumn{2}{|c|}{ NA } & \multicolumn{2}{|c|}{ NA } \\
\hline
\end{tabular}

Statistics non-applicable because of constant findings

Table (5): Inter-rater agreement test after 72 hours of demineralization D1 vs. D3

\begin{tabular}{|c|c|c|c|}
\hline & \multicolumn{2}{|c|}{ EDX } & \\
\hline & -ve & +ve & \\
\hline \multicolumn{4}{|l|}{ DIAGNOcam } \\
\hline - No caries & 0 & 0 & $0(00.0 \%)$ \\
\hline \multirow[t]{3}{*}{ - Caries } & 0 & 60 & $60(100.0 \%)$ \\
\hline & 0 & 60 & 60 \\
\hline & Value & $95 \% \mathrm{CI}$ & \\
\hline Sensitivity & $100.00 \%$ & $\begin{array}{c}0.88 .43 \%- \\
100.00 \%\end{array}$ & \\
\hline Specificity & NA & & \\
\hline Positive likelihood ratio & 1.00 & & \\
\hline Negative Likelihood ratio & NA & & \\
\hline Disease prevalence & $100.00 \%$ & $88.43 \%-100.00 \%$ & \\
\hline Positive predictive value & $100.00 \%$ & & \\
\hline Negative predictive value & NA & & \\
\hline Overall accuracy & $100.00 \%$ & $\begin{array}{c}0.88 .43 \%- \\
100.00 \%\end{array}$ & \\
\hline
\end{tabular}

Weighted kappa $=0.000$

The $\mathrm{Z}$ test is N/A (non-applicable due to exact match)
Accuracy of D2 vs. D3 as shown in table (3): At the mesial sides, statistical comparison of the two diagnostic means D2 and D3 showed that D3 is more accurate than D2 in detection of early carious demineralization and the differences are statistically significant. $(\mathrm{X} 2(\mathrm{Y})=22.63, \mathrm{P}$ $(Y)=0.000 *)$. At the distal sides, statistical comparison of the two diagnostic means D2 and D3 showed that D3 is more accurate than D2 in detection of early carious demineralization and the differences are statistically significant. $(\mathrm{X} 2(\mathrm{Y})=22.63, \mathrm{P}(\mathrm{Y})=0.000 *)$. At both mesial and distal sides, statistical comparison of the two diagnostic means D2 and D3 showed that D3 is more accurate than D2 in detection of early carious demineralization and the differences are statistically significant. (X2 (Y)=48.82, P $\left.(Y)=0.000^{*}\right)$ Statistical comparison regarding the validity in detection of early carious demineralization showed that the overall accuracy of D3 (100.00\%) is significantly higher than the accuracy of D2 (6.67\%) within 95\% confidence interval.

Table (3): Pearson's Chi square test of significance after 72 hours of demineralization D2 vs. D3.

\begin{tabular}{|c|c|c|c|c|c|c|}
\hline & \multicolumn{4}{|c|}{ Side } & \multirow{2}{*}{\multicolumn{2}{|c|}{ All }} \\
\hline & \multicolumn{2}{|c|}{ Mesial } & \multicolumn{2}{|c|}{ Distal } & & \\
\hline & $\mathbf{N}$ & $\%$ & $\mathbf{n}$ & $\%$ & $\mathbf{n}$ & $\%$ \\
\hline $\begin{array}{l}\text { (D2) X-ray } \\
-\quad \text { No caries } \\
-\quad \text { Caries } \\
\end{array}$ & $\begin{array}{c}28 \\
2 \\
\end{array}$ & $\begin{array}{c}93.33 \\
6.67 \\
\end{array}$ & $\begin{array}{c}14 \\
1\end{array}$ & $\begin{array}{c}93.33 \\
6.67\end{array}$ & $\begin{array}{c}56 \\
4 \\
\end{array}$ & $\begin{array}{r}93.33 \\
6.67 \\
\end{array}$ \\
\hline $\begin{array}{l}\text { (D3)DIAGNOcam } \\
- \text { No caries } \\
- \text { Caries } \\
\end{array}$ & $\begin{array}{c}0 \\
30\end{array}$ & $\begin{array}{c}0.00 \\
100.00 \\
\end{array}$ & $\begin{array}{c}0 \\
15 \\
\end{array}$ & $\begin{array}{c}0.00 \\
100.00 \\
\end{array}$ & $\begin{array}{c}0 \\
60 \\
\end{array}$ & $\begin{array}{c}0.00 \\
100.00 \\
\end{array}$ \\
\hline Test of significance & \multicolumn{2}{|c|}{$\begin{array}{l}\mathrm{X} 2(\mathrm{Y})=22.63 \\
\mathrm{p}(\mathrm{Y})=0.000^{*}\end{array}$} & \multicolumn{2}{|c|}{$\begin{array}{l}\mathrm{X} 2(\mathrm{Y})=22.63 \\
\mathrm{p}(\mathrm{Y})=0.000^{*}\end{array}$} & \multicolumn{2}{|c|}{$\begin{array}{l}\mathrm{X} 2(\mathrm{Y})=48.82 \\
\mathrm{p}(\mathrm{Y})=0.000^{*}\end{array}$} \\
\hline
\end{tabular}

$\mathrm{X}$ 2: Pearson's Chi square

*: Statistically significant $(\mathrm{P}<0.05)$

\section{DISCUSSION}

Detection of carious lesions on neighboring approximal surfaces of human teeth is a challenge (5), conventional methods of detecting caries are underestimating, causing some caries to go undetected until it has reached more advanced stages, requiring surgical intervention that destruct the tooth structure in order to restore it (14). Noninvasive treatment of early caries lesions by remineralization has become of major importance in clinical daily practice, where many studies in turn would prevent white spot lesions formation and further cavitation, but instead, remineralize the existing lesions eliminating the need to restore the tooth (7). There is a need for a diagnostic tool that can clinically detect the earliest carious lesions in order to reach the goal of not restoring a tooth and instead treat and remineralize it.

Two laboratory (EDX and SEM) and two clinical (X-ray and DIAGNOcam) diagnostic tools used in our study. Calcium and Phosphorus ions ratios by EDX in all selected visually sound teeth were more than 1.80 . This coincides with ten Cate, JM et al (9) and Jalevik, B. et al (10) who stated that a ratio equal to or above 1.8 was considered normal healthy enamel, while Shellis, RP et al (15) and de Sant'Anna, G. et al (16) stated that 1.67 was enough for the tooth to be considered healthy.

Digital radiography images obtained from the same previously visually examined sound teeth also showed images of sound enamel in all the specimens. 
DIAGNOcam images obtained from the same previously visually examined sound teeth also showed images of sound enamel in all the specimens. Therefore, the thirty three teeth were accepted in the study. The SEM images obtained from the randomly selected specimens confirmed the results obtained from EDX, Digital x-ray and DIAGNOcam.

The same results were obtained by EDX coincided with those obtained by digital radiography, DIAGNOcam and SEM, this ranks DIAGNOcam as a diagnostic tool for detection of sound enamel. A dark room setting was used during DIAGNOcam detection to obtain reasonable images simulating the conditions of the oral cavity.

Our findings after 72 hours of demineralization showed that; EDX used as a laboratory diagnostic tool for Calcium and Phosphorus ions concentration, detected all the changes in their concentrations, this may be due to the high sensitivity of this diagnostic tool, which coincides with Bloehaum, R. et al (17) who stated that EDX measurements are used to obtain exact $\mathrm{Ca} / \mathrm{P}$ ratios.

Digital radiography images diagnosed two surfaces out of thirty after 72 hours demineralization with radiolucency of the early demineralized enamel. Statistical comparison between EDX and digital radiography showed that digital radiography had a much lower sensitivity in detecting radiolucency of early enamel demineralization and there is a statistically significant difference, this may be due to the fact that digital x-ray can't detect the earliest changes that occur on the surface of enamel, which coincides with Hintze, H. et al (18) who stated that radiography seemed to be of almost no value in the detection of the enamel approximal lesions.

DIAGNOcam images detected radiolucency of the early enamel demineralization with high sensitivity after 72 hours of demineralization exactly that same as EDX, Statistical comparison of the results obtained by the DIAGNOcam with those of the EDX was not applicable as both methods showed exact match in their results in diagnosing early enamel demineralization, that may be due to the penetration power of LASER beam at $780 \mathrm{~nm}$, which has the ability to pass through the affected approximal enamel demineralization and image it. This was also confirmed by the results of the SEM, which may consider DIAGNOcam as sensitive as the EDX and SEM that are considered as gold standard. This coincides with $\mathrm{Yu}$, JL. et al (19) who concluded that there was no significant difference between the depth of caries lesions checked with DIAGNOcam and the depth of the actual cavity. Also, Russotto, F. et al (20) who concluded that near-infrared transillumination performed significantly better than radiography as an interproximal caries detection tool. Also, Marinova-Takorova, M. et al (21) who concluded that nearinfrared transillumination is an effective method for diagnosis of lesions both involving only the enamel and involving the enamel and dentin for both occlusal and proximal caries lesions. Also, Simon, J. et al (22) who stated that near-infrared imaging was significantly more sensitive than radiography in detecting early carious lesions on both occlusal and interproximal surfaces, and Cirligeriu, L. et al (23) who found that there is a good correlation between near-infrared transillumination and radiography but the former proved more accurate compared to the later. On the other hand, Jost, F. et al (24) disagreed and concluded that agreement with NIR-TI was worse compared to Bitewing digital radiography $(\mathrm{BW})$. But, they owed this for the missing calibration of their examiners and shadow artifacts in the margins of the teeth in some NIR-TI images.

The SEM images obtained from the randomly selected specimens confirmed the results obtained from the EDX and DIAGNOcam, this may be due to the high sensitivity of DIAGNOcam in detection of early demineralized enamel.

\section{CONCLUSION}

1.Early demineralization of enamel carious lesions can't be detected by visual examination nor by digital radiography where digital near-infrared transillumination (DIAGNOcam) detection will help us to confirm it.

2.Near-Infrared Transillumination (DIAGNOcam) is a digital dental diagnostic device that will allow the application of the "rule not to restore" taking advantage of the depth of penetration of its LASER beam at $780 \mathrm{~nm}$ to detect the earliest stages of enamel demineralization to perform a true "micro-minimally invasive" line of treatment.

3.Near-Infrared Transillumination (DIAGNOcam) could provide us with a radiation free method that helps in the early detection of enamel carious lesions allowing us to diagnose and treat the affected surfaces instead of filling them.

4.Near-Infrared Transillumination (DIAGNOcam) can be used for monitoring the "corrective treatment" of the demineralized enamel carious lesions until sound enamel is obtained.

\section{CONFLICT OF INTEREST}

The authors declare that they have no conflicts of interest.

\section{REFERENCES}

1. Featherstone JD. The science and practice of caries prevention. J Am Dent Assoc. 2000;131:887-99.

2. Holmen L, Thylstrup A, Øgaard B, Kragh F. A scanning electron microscopic study of progressive stages of enamel caries in vivo. Caries Res. 1985;19:355-367.

3. Robert H Selwitz, Amid I Ismail, Nigel B Pitts. Dental caries. Lancet 2007;369:51-9.

4. Zandoná AF, Zero DT. Diagnostic tools for early caries detection. J Am Dent Assoc. 2006;137:1675-84.

5. Bader JD, Shugars DA, Bonito AJ. Systematic reviews of selected dental caries diagnosis and management methods. J Dent Educ. 2001;65:960-68.

6. Douglass CW, Valachovic RW, Wijesinha A, Chauncey $\mathrm{HH}$, Kapur KK, McNeil BJ. Clinical efficacy of dental radiography in the detection of dental caries and periodontal diseases. Oral Surg Oral Med Oral Pathol. 1986;62:330-9.

7. Patel S. Management of the precavitation lesion. Saudi Dent J. 2000;12: 37-47.

8. Iain A. Pretty. Caries detection and diagnosis: Novel technologies. J Dent. 2006;34:727-39.

9. Ten Cate Jm, Duijsters PP. Alternating demineralization and remineralization of artificial enamel lesions. Caries Res. 1982;16:201-10.

10. Jälevik B, Odelius H, Dietz W, Norén J. Secondary ion mass spectrometry and X-ray microanalysis of hypomineralized enamel in human permanent first molars. Arch Oral Biol. 2001;46:239-47.

11. Murdoch-Kinch CA, McLean ME.. Minimally invasive dentistry. J Am Dent Assoc. 2003;134:87-95.

12. Leuridan F, Colombel D, Lion B. Nail varnish comprising an aqueous polymer dispersion. United States patent US. 
2002; 6,372. Available at:

https://www.google.ch/patents/US6372201

13. Maia AM, Karlsson L, Margulis W, Gomes AS. Evaluation of two imaging techniques: near-infrared transillumination and dental radiographs for the detection of early approximal enamel caries. Dentomaxillofac Radiol. 2011;40:429-33.

14. White JM, Eakle WS. Rationale and treatment approach in minimally invasive dentistry. J Am Dent Assoc. 2000;131:13S-9S.

15. Shellis RP, Wilson RM. Apparent solubility distributions of hydroxyapatite and enamel apatite. J Colloid Interface Sci. 2004;278:325-32.

16. de Sant'Anna GR, dos Santos EA, Soares LE, do Espírito Santo AM, Martin AA, Duarte DA, et al. Dental Enamel Irradiated with Infrared Diode Laser and Photo-Absorbing Cream: Part 2-EDX Study. Photomed Laser Surg. 2009;27:771-82.

17. Bloebaum RD, Skedros JG, Vajda EG, Bachus KN, Constantz BR. Determining mineral content variations in bone using backscattered electron imaging. Bone. 1997;20:485-90.

18. Hintze H, Wenzel A, Jones C. In vitro comparison of D-and E-speed film radiography, RVG, and visualix digital radiography for the detection of enamel approximal and dentinal occlusal caries lesions. Caries Res. 1994;28:363-7.

19. Yu JL, Tang RT, Feng L, Dong YM. Digital imaging fiber optic transillumination (DIFOTI) method for determining the depth of cavity. Beijing Da Xue Xue Bao Yi Xue Ban. 2017;49:81-5.

20. Russotto F, Tirone F, Salzano S, B̆orga FC, Paolino D, Ferraro A, Botasso S. Clinical evaluation of near-infrared light transillumination (NIRT) as an interproximal caries detection tool in a large sample of patients in a private practice. J Radiol Imaging. 2016;1:1-5.

21. Marinova-Takorova M, Panov V, Anastasova R. Effectiveness of near-infrared transillumination in early caries diagnosis. BIO. 2016;30:1207-11.

22. Simon JC, Lucas SA, Lee RC, Darling CL, Staninec M, Vaderhobli R, et al. Near-infrared imaging of secondary caries lesions around composite restorations at wavelengths from 1300-1700-nm. Dent Mater. 2016;32:587-95.

23. Cirligeriu L, Sinescu C, Boariu M, Negrutiu ML, Nica L. The Importance of Early Diagnosis for Hydroxyapatite Remineralisation in Enamel Caries. Revista de Chimie. 2015.

24. Jost FN, Kühnisch J, Lussi A, Neuhaus KW. Reproducibility of near-infrared light transillumination for approximal enamel caries: a clinical controlled trial. London, UK ConsEuro 2015. Available at: http://www.epostersonline.com/conseu2015/node/686?vie $\mathrm{w}=$ true 